\title{
Management of Gen Y Employees through Psychological Contract - 'An Exploratory Study in IT/ITES Companies'
}

\author{
Jyoti Joshi Pant ${ }^{1 *}$ and V. Vijaya ${ }^{2}$ \\ 'Prin. L. N.Welingkar Institute of Management Development \& Research, Bengaluru, India \\ ${ }^{2}$ IIM-T,Tamil Nadu, India
}

\begin{abstract}
:
Globalization has led to diverse workforce for most of the multinational corporations. Today's workforce is highly diverse based on Gender, Race, Ethnicity, Nationality, Age, Physical capabilities at a surface level and values, attitudes, personality, education and religion at a deeper level.

Diversity Management means valuing the differences in people. In India, Diversity mostly referred to gender related initiatives in the past. But today companies are moving to include national culture, age, physical ability and sexual orientation. In the context of generational diversity, four generations exist at workplace today namely the Veterans, Baby Boomers, Gen X and Gen Y. Gen Y is born between 1980 and 2000 make up 25\% of the world population and nearly half the Indian population. They will soon form the largest employee base for organizations around the globe. However there is lack of substantial academic research on Indian Gen Y. Purpose: The study tries to explore and understand the important workplace expectations of Gen Y through the lens of psychological contract. 11 focus group discussions were held with 89 Gen Y employees currently working in IT/ITES companies. It further explores the unique expectations of Gen Y women and Gen Y differently-abled employees which may contribute to the unique elements in their psychological contract. Research Design/Methodology: Focus Group Discussions Exploratory study Findings: The study revealed that Salary, Career Growth, Opportunities at work, Job Satisfaction and Work Life Balance emerged as the top expectations of Gen Y as a whole. However it was interesting to note that when comparison was made between men, women and differently-abled employees within Gen $\mathrm{Y}$, the expectations were completely different with only challenging work being common to all the three groups. Research Limitations: This study is an exploratory study with focus groups and qualitative data. A further large scale cross sectional study needs to be done with quantitative analysis to confirm the important workplace expectations of Gen Y. Study is limited to IT/ITES employees in Bengaluru. Only three specific employee groups under Gen Y namely men, women and differently-abled were explored due to time constraints. Studies in the future can include more employee groups like ex-army employees, employees from rural and urban background, LGBT etc. Practical Implication: If IT/ITES organizations want to attract engage and retain young Gen Y employees, they must proactively understand the needs and expectations of these youngsters. It is also critical that specific needs of various employee groups within Gen Y are also understood and met. Originality: Until now most organizations have had a reactive approach to managing diversity either as a response to a minority discrimination case or legal compliance. The paper argues for a more proactive approach to managing Generation Y expectations using psychological contract framework which has never been proposed before.
\end{abstract}

Keywords: Differently-Abled Employees, Diversity Management, Gen Y, Women, Psychological Contract, Workplace Expectations

"E-mail: jyoti.pant@welingkar.org 


\section{Introduction}

With the event of globalization, many companies throughout the world have used a multinational strategy to enter new geographies and succeed in business. This has translated into a diverse workforce. Today's workforce is highly diverse in terms of Race, Ethnicity, Nationality, Gender, Age, Physical capabilities, Values, Attitudes, Personality, Religion, Educational level and Job tenure. (Ivancevich and Gilbert, 2000).

Employee experience differs at work in terms of how they perform, what motivates them and how they communicate with each other. All these differences make up for the diversity at workplace (Harvey and Allard, 2009).

In a highly competitive workplace, today organizations have no option but to adapt their management practices and policies to the needs of the $21^{\text {st }}$ century employee. Over the last 10-15 years there has been an increase in the diversity initiatives in western countries both the private and public sector. Many large company both in public and private sector now either have a diversity and inclusion council internally or seek help of external diversity consultants to aid the firm in promoting diversity values and creating and inclusive culture (Roberts, 2011). In India too, there is a general agreement among employers that diversity and inclusion has a business rationale for the organization. Employees overwhelmingly expressed pride in working for an equal opportunity employer demonstrating a strong association and connect. (NASSCOM, 2011).

Diversity Management means valuing the differing perspectives of people in organizations. It aims to create an environment at workplace such that all employees are able to achieve their full potential. In simple terms it means that different people in the society are not made to melt their differences and taste like a mixed soup. Rather it accepts and celebrates the differences in people at workplace. Diversity management also tries to focus on the economic benefits reaped by an organization where all employees are able to contribute in their full capacity together (Woodward and Saini, 2006).

A Diversity and Inclusion report by Mercer on the Asian Pacific Perspective states that it is only after 2005 that evi- dence of real diversity and inclusion agenda among some companies in the Asian region began to emerge. Thus Diversity is a relatively new concept and its meaning varies widely. While in some countries "Diversity" as a term and practice does not exist, in Singapore it means "fair employment practices" while in India and Japan it refers mostly to gender related initiatives. Mercer interviewed 31 companies during this survey and found that $66.2 \%$ of them had a diversity and inclusion strategy at a Global and Regional Level. However diversity efforts have focused on various dimensions: $74 \%$ on gender, $45 \%$ on national culture, $40 \%$ on race, $32 \%$ on age, $17 \%$ on disability and $4 \%$ each on sexual orientation and religion. According to the report, legislation drove Diversity Initiatives in more mature economies like the US and Europe. In the absence of legislation in Asia, the drive for diversity in purely related to business needs (Mercer, 2012).

\section{Review on Literature}

\subsection{Diversity and it's Contribution to Business}

The business case for diversity argument works at three levels: Firstly intense competition for good talent has forced organizations to look beyond the regular sources. Secondly, organizations wanting to effectively serve a global customer base also need their employees to be diverse so that they can understand the needs their customer. A third argument is that since innovation is being chased by most companies, a group of people from different demographic backgrounds unleashes creativity, innovation and improved group problem solving (Konrad, 2003).

In addition to the above, in a multicultural society an attempt to increase workforce diversity is socially the most acceptable way of managing differences and is also ethically the right thing to do as corporate citizens, regardless of the economic implications of the decision (Jayne and Dipboye, 2004).

According to NASSCOM (The National Association of Software and Services Companies), following are the current drivers for Diversity in India (NASSCOM, 2011):

1. Non availability of talent.

2. Changing demographics.

3. High customer expectation. 
4. Globalization of business.

5. Sustainability.

6. Innovation.

NASSCOM Corporate Awards are India's only awards in the diversity space and have created a platform for hundreds of organizations to share their experience and initiatives in managing Diversity and building an Inclusive culture since 2007. According to their 2011 report, the predominant area of focus in the Indian Diversity context has been gender, unlike the west where cultural diversity is more prominent. The industry is now increasing focus on newer areas within diversity such as economic-status, age or generational diversity and inclusion of persons with disabilities" (NASSCOM, 2011).

Based on the above discussion it can be understood that diversity is a reality today for most organizations. In fact today organizations have realized that diversity is not a problem to be managed but an opportunity that must be utilized.

\subsection{Managing Employee Diversity through the Psychological Contract}

Employee expectations play an important role in the formulation of the psychological contract under Human Resource Management. Expectations feature as an important part of the psychological contract (Grant 1999, Sparrow 1996). A heterogeneous set of employees in a company come with its own unique skills sets and attributes. The psychological contract can be utilized as a useful framework to understand the expectations of diverse groups of employees and thereby manage them better. Therefore, it is quite important to understand the variations in their expectations, so that they can be understood individually as well as collectively for effective functioning.

Psychological contract is the 'implicit contract between an individual and his organization which specifies what each expects to give and receive from each other (Kotter, 1973).In the recent years, Rousseau (1990) revived the interest in the concept and defined Psychological Contract as the individual's beliefs that he/she owes to the employer in form of contributions like hard work, loyalty and sacrifices in return for certain inducements like high pay and job security. Psychological contract exists in the eyes of the employee and it is the employee's belief in psychological contract which affect his or her attitude and behavior. Mutuality between employer and employee is not required since psychological contract is about individual's beliefs, shaped by the organization regarding terms of an exchange agreement between individuals and their organizations (Rousseau, 1995).

The psychological contract is usually incomplete at the beginning of the employment and gets shaped over the course of employment. Neither the employee nor the employer can initially spell out the exhaustive elements and details of a long term employment relationship. Expectations regarding work get formed during the initial discussions between the candidate and the recruiter at the recruitment and selection phase. This discussion leads to a better understanding of the company policies and code of conduct and sets background regarding the expected behaviors of both the employee and employer in the future. It forms a part of the psychological contract for the individual getting into an employment relationship. As time passes, members of Top management, HR managers, one's immediate boss as well as colleagues act as information sources on behalf of the organization. Thus as the employment progresses, all of them help in shaping the psychological contract of the employee. Both parties believe they will do their best to fulfill their part of the obligations (Rousseau 1990, 2004).

Since the psychological contract keeps changing along the employment period, it is important that the organization regularly checks the satisfaction levels of their employees on their expectations and their fulfillment. The organizations can have frank discussions with the employees and understand their expectations and find out the changes to the contract over time (Sims, 1994). The fulfillment of expectations by both the parties can become a building block for a strong organization where the employer take good care of the employees who in turn are highly committed to their organization (Rousseau 1990, 2004).

Literature on Psychological contract indicates that it has been studied primarily from three angles. Feature orientation, evaluation orientation and content orientation (Rousseau and Tijorwala1998, Freese and Schalk 
2008). In the feature orientation, studies have focused on whether the contract is long term and relational, short termed or transactional. A balanced contract has mixed elements of both. (Rousseau 1990, Rousseau and Tijoriwala 1998, Rousseau 2004, Ho 2005, Patrick 2008, Lee and Faller 2005).

Another set of studies researched on the evaluation of fulfillment of the contract and its breach and violation. They tried to indicate how employees would react if organization are unable to keep their promises and fulfill the expectations of the employees. Studies indicated that it would lead to decreased job satisfaction, reduced trust and loyalty, decreased intention to remain with the organization and increased turnover (Turnley and Feldman 1999, Mason 2003, Robinson and Rousseau 1994, Lester et al. 2002, Robisnson and Morrison 2000).

Studies done to understand the contents of the psychological contract and expectations have revealed that consistently in literature career development, job content, high salary and financial rewards, good benefits, flexibility, training, job security, supportive work culture, sufficient resources and support with personal problems are some of the expectations employees have from their employers. (Rousseau 1990, Herriot et al. 1997 Lester and Kickul 2001, Roehling et al. 2000, Patterson and George 2002, Atkinson and Cuthbert 2006, Branka et al. 2009, De Vos et al. 2003, Freese, and Schalk 2008, De Vos, et al. 2009, Cynthia Lee et al. 2011).

However very few studies have tried to study if these expectations and content of psychological contract differs for various groups of employees within the organization. A study on the contents of psychological contract done by Branka (2009) indicated that there were differences in the expectations among academicians and sensitivity to such variations is important if organization wants to achieve its goals. Another study by Atkinson and Cuthbert (2006) revealed that content of psychological contracts differ for different employee groups based on their hierarchy in the organization namely the mangers, supervisors and shop floor workers. There is a need to study if psychological contract of women, men and differently-abled employees differ from each other and what elements make them unique.
Very limited literature is available on Psychological contract in India. A study by Aggarwal and Bhargava (2009) indicated thirty three workplace expectations from organizations which were combined into following four factors: Growth and Developmental Opportunities, Supportive work culture, Salary and benefits and Resource availability as the primary expectations from workplace for Indian Employees which was in line with the global studies. However the study revealed that while employer's consider maintaining fair and equitable organizations as their main responsibility, for employees growth and developmental opportunities are most important. Thus the study also indicated that there was incongruity among employee and employer expectations. It study also raised the need for future research studies to study the influence of gender and individual factors on contents of the psychological contract.

A study by Mason in 2003 examined the psychological contract held by minority employees based on their race. The study supported that minority employees may have unique elements of the psychological contract with respect to diversity related promises. Minority employees felt that fewer diversity related promises were fulfilled and this perception of breach of contract led to higher job dissatisfaction and lower organizational commitment among employees. The study indicated the need for additional research to clarify further on the important aspects of psychological contract to person of color (Mason, 2003).

Thus based on the above discussion, it can be inferred that from a diversity management viewpoint the elements of the psychological contract may be unique for employee groups like Gen Y, Women, differently-abled etc. This preliminary study aims to explore the psychological elements of Gen Y in India and understand the how these expectations may be different for women and differently-abled employees. This exploratory study is unique in its attempt to call for a more proactive approach to Diversity Management of employees by understanding the unique psychological contract expectations of employees. An understanding of these unique expectations and their fulfillment can help organizations create more job satisfaction and commitment among these employee groups. 


\subsection{Psychological Contract and Workplace Expectations of Gen Y}

The new entrant to the workforce is Gen Y. It consists of individuals born during the twenty years spanning from 1980-2000 (Erickson, 2008). Various authors have labeled them as Gen Y, Millennia's and Gen Me (Tulgan 2004, Raines 2002, Twenge and Campbell 2008). For the purpose of this study, the term Generation Y or Gen $\mathrm{Y}$ has been used.

Gen Y's is highly independent and entrepreneurial in nature. They take on responsibility to prove their skills and talent. They demand immediate feedback and thrive on challenging work. They love freedom and flexibility and do not like to be micromanaged. If managed well they can be highly productive (Martin, 2005).

However Gen Y has higher expectations than even before (Meier, Austin, and Crocker, 2010). The new entrant to workforce Gen Y has different expectations which if not understood well may lead to a further erosion of the psychological contract between the manager and the employee. Most of the studies have studied Gen Y while they were in college and therefore there is a need to study Gen Y once they enter into full time work. Literature also point to the need to see if gender, race and income affect the perception of Gen Y (Eisner, 2005; Josiam et al. 2009).

Most of the studies conducted on Gen $\mathrm{Y}$ have been done in the west. There is a need to study Gen Y in their cultural context because generations in different countries around the world (Deal, Altman, and Rogelberg, 2010). There is an urgent need to understand Indian generations and look at the demographic, economic and regional differences within India while studying different generations (Srinivasan, V. 2012).

There is lack of substantial research on the Indian Gen Y. A study on Gen Y in India revealed that it expects more from employers than the previous generations (Saxena and Jain, 2012). Another study on Indian Gen Y revealed that their expectations from the job and the employer are much higher and also volatile. When asked to rank expectations, Gen Y chose learning opportunities in the job and career growth as the most important expectation (Mamtha, J.; Dr. Satya Nandini, A. 2013).

Therefore the following study makes an attempt to explore the workplace expectations of Gen Y in India currently working in the IT/ITES sector by using psychological contract framework. It aims to use this knowledge to managing workplace diversity among Gen Y employees which is highly under researched in India by the academics.

\section{Objectives of the Study}

Gen $\mathrm{Y}$ are the future employees of organizations across the globe. Most of the studies conducted on Gen Y have been done in the west. There is a need to study the young employees in the Indian cultural context.

With more women, youngsters from rural and socioeconomic background gaining easy access to education and opportunities for work, this generation may be one of the most diverse workforce generations ever to work in corporate India so far. As studies point out, sometimes there is also more variability within a generation than there is between generations and therefore we must not make the mistake to assume that everyone in a generation is similar (Deal, Altman, and Rogelberg, 2010). Therefore it will be too naïve to consider that all members of Gen Y shared common expectations from workplace.

Therefore the aim of this study is:

- To identify the important workplace expectations of Gen Y employees.

- To explore variations in expectations among Gen Y women employees.

- To explore variations in expectations among employees who are physically differently-abled.

\section{Research Design of the Exploratory Study}

- The Sector: Information Technology and Information Technology Enabled services (IT and ITES). 
- The number of employees who participated in the discussion was: 89 employees.

- The number of focus group discussions conducted: 11.

- Gen Y's are people born between the years 19802000. The age range of the participants is 34 years and below.

- The number of companies that participated: 6 companies from IT/ITES industry.

\section{Focus Group Discussion Methodology}

The first level involved contacting IT/ITES companies and proposing them the benefits of the study on Gen Y expectations in India. Based on the success in the initial stage, collaborated effort with 6 firms was made to conduct 11 group discussions at their location with their Gen Y employees. Each focus group had heterogeneous participation from 8-15 employees. Two focus groups were conducted with only female employees, another two with only male employees and another two with differently-abled employees to understand their unique expectations.

Discussion generally ranged from 45 minutes to 1.5 hours. At the first level it was exploratory with a free flow of checking with them their most important expectations from the company and work. The FGD also involved probing further on many concepts; for example career growth, on what it meant for employees.

Attempt was made to see that most of the participants in the group gave their views and number of votes or counts per view were also roughly estimated during the process and were recorded. In some cases, quick notes were taken and in others, audio and video recording was also done, the text of which was transcribed the next day to avoid loss of data.

\section{Factors and Expectations Identified during the Exploratory Study}

We present below the definition of the expectations that were explored as part of this study.

\subsection{Compensation and Remuneration}

We define compensation and remuneration as the monetary component that is provided to the employees in exchange for the services offered, which has two parts one of which could be fixed as per company norms and the other variable, which differs with employee contribution.

\subsection{Good Work Environment}

We define good work environment as the context at work which includes the physical, psychological and social experience of the employee while he/she spends time working for the organization.

\subsection{Career Growth}

We define career growth as the transition to a higher level in one's role or profile at work with added responsibilities and challenges with concomitant compensation.

\subsection{Transportation}

We define transportation as the facilitation and facility offered to the employee to reach the workplace.

\subsection{Challenging Job}

Based on the inputs from the respondents, we define challenging jobs as those that are more demanding and complex, which requires additional skills and knowledge than what is being used in the present role, which helps the employee to enhance knowledge and skill sets.

\subsection{Job Security}

Based on the inputs we define job security as sense of assurance that an organization provides to the employee about the longevity of the employment contract.

\subsection{Recognition}

We define recognition as the provision of positive cues and acknowledgement to the contribution of the employee at work, usually by the manager to whom one reports at work.

\subsection{Work Life Balance}

We define work life balance as a physical and psychological state of employees where they perceive that they 
are able to satisfactorily contribute as an employee as well as satisfy the role requirements as a family member and any other roles in life.

\subsection{Area of Specialization}

We define area of specialization as the opportunity and state of experiences offered to employees to develop expertise in certain areas or domains through added experience at work.

\subsection{Job Satisfaction}

We define job satisfaction as the level of contentment experienced by employees while performing their job and fulfilling role requirements.

\subsection{Designation}

We define designation as the official term or label offered for various roles which has social and status connotations.

\subsection{Opportunities at Work}

We define opportunities at work as the number of experiences at work offered to the employee in qualitative and quantitative terms to improve and develop one's knowledge and skill sets.

\section{Findings from the Exploratory Study}

\subsection{Focus Group 1}

This was a mixed focus group representing employees from various IT/ITES companies. Compensation emerged as the most important expectation for 33\% of the employees in the group. This was followed by good work environment for $22 \%$ employees. Career growth, Challenging job, transportation and flexibility at work were also mentioned as important expectations by some employees (Figure 1).

\subsubsection{Compensation and Remuneration}

Gen Y employees prefer variable pay based on performance. In addition to paying competitive market salary, the employees want the organization to be more transparent in telling them their take home salary. The organizations many times never tell the employees the true take home salary. After getting their first pay check the employees realize that due to the high deductions their take home is low. This creates distrust for the employer among the employees.

Gen $Y$ employees want the organization to give them the option of choosing benefits and components of salary which they prefer. While cash component is always

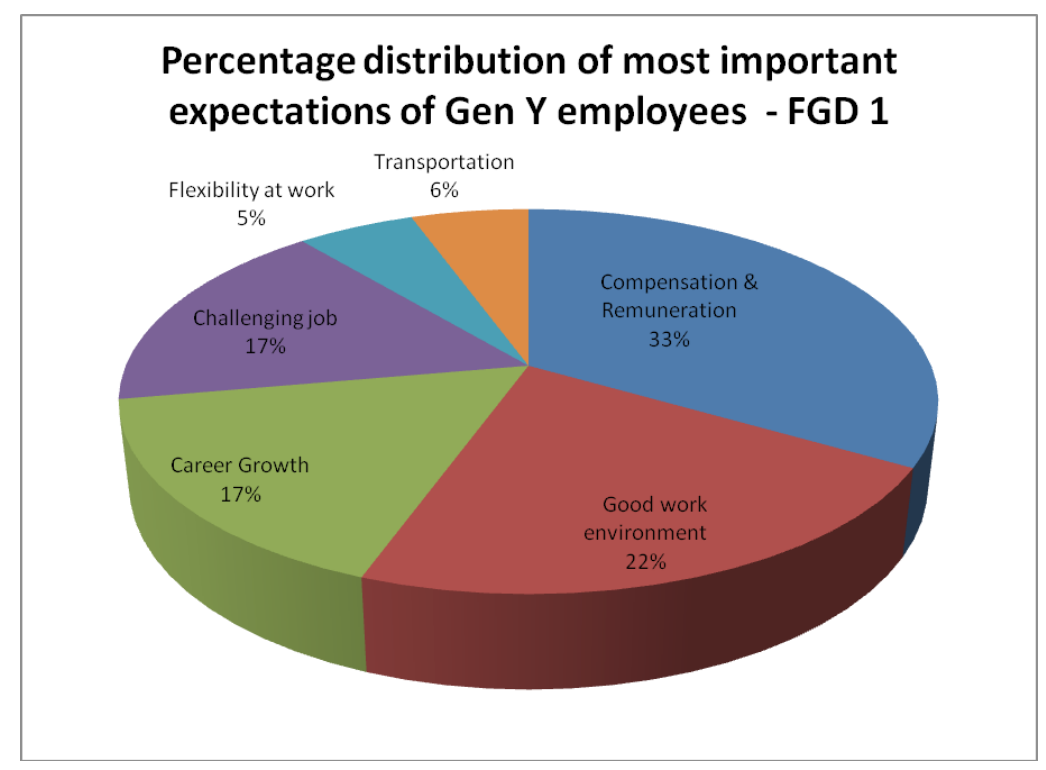

Figure 1. Percentage disrtibution of most important expectations of Gen Y employees - FGD1. 
good, some people feel movie tickets, restaurant passes, ID card discounts at stores etc. are good because they also give an opportunity for employees to socialize beyond regular work.

Accommodation, food laundry, gyms, as well as day care for children seem to be very important. Healthcare benefits are very important. Employees want the organization to cater to the needs of diverse employees in the organization.

\subsubsection{Good Work Environment}

For Gen Y employees, good working conditions include a cheerful atmosphere. Many times employees greet the boss and there is no response in return. Positivity in the workplace is important. In one employees company there is a culture of greeting everyone in the morning. People even greet others in office that they don't know personally. They are called smile friends. Some smile friends even send emails when they quit the company. Thus culture and workplace practices that are consciously created are found to be valuable by the employees. It could have an impact on work and productivity.

Additionally, employees want workplaces to be spacious and clean. Work timing is important but when an employee is late, the prefer the manager to ask if everything if there is a problem and if everything is ok rather than pointing that the employee is late to work. Good working conditions would help me grow as an individual.

\subsubsection{Career Growth}

Career growth for Gen Y means that employees are able to develop their career stream. They are able to make good use of the available resources at work. They want that the work helps to improve their skills and attitude over a period of time and enable them to gain new knowledge as well.

\subsubsection{Transportation}

Transportation is important for some Gen Y employees. However it is also dependent upon the city of work. It is crucial if one is working in Metro or Tier 1 city like Bengaluru while in Tier 2 city it is not so important.

\subsubsection{Challenging Job}

Gen Y employees believe that jobs must have targets set by the managers which are achievable. Sometime very difficult targets can pressurize the employee and make him think himself as incapable so much so that he/she quits. Employees do not want difficult targets be used by managers as an excuse for laying-off the employees. Monotonous work becomes boring. The employees prefer that organizations provide for variety of work. $68 \%$ people in the group preferred job rotation as against $38 \%$ who prefer to become specialists in their domains. Employees want to come out of their comfort zone and try something new. They want to challenge themselves to do something new and take risks. They want the organizations to provide appropriate conditions for this to happen.

\subsection{Focus Group 2}

This was a focus group representing employees from a single IT firm with both male and female employees.

Career growth was voted as the most important expectation from work by almost $50 \%$ of the participants. $25 \%$ indicated salary to be very important. Job security and recognition also were discussed as most important expectations from work by few employees.

\subsubsection{Career Growth}

Good career growth for Gen Y means greater exposure for the employee.

\subsubsection{Compensation and Remuneration}

One participant preferred no security of job but a huge take home salary so that he can spend it on his friends.

\subsubsection{Job Security}

If given a choice between high salary and job security: $62.5 \%$ of Gen Y preferred job security to a higher salary.

\subsubsection{Recognition}

Recognition was rated as extremely important by some Gen Y participants. The employees prefer the recognition to come from colleagues, CEO and Managers. They 
consider the manager to be responsible for ensuring that the recognition comes to the right person. Usually in organizations all credit goes to the Team manager rather than the Team leader. The manager works from home and many times does not know what each team member is doing. Recognition is preferred quarterly. Doing it monthly or weekly will dilute its charm.

\subsection{Focus Group 3}

This was a focus group representing employees from a single ITES company including of both male and female employees. Career growth was the most important expectation for $31 \%$ of the employees in this group followed by Remuneration and Job satisfaction for 23\% each participants. Challenging work, no politics and less pressure at work were some other important expectations for few employees.

\subsubsection{Career Growth}

For this group of Gen Y employees meant getting into a higher role, more responsibility at work. It also meant greater exposure both domestic and overseas. Greater exposure would mean that employees also get the ability to work with more clients and also travel abroad.

\subsubsection{Compensation and Remuneration}

Compensation and remuneration means money. More money is important if one changes the job. With more money also comes more responsibility as we progress.

\subsection{Focus Group 4 and 5}

There were two focus group conducted at this IT organization. The focus group consisted exclusively women employees to understand the impact of gender on workplace expectations. Work life balance emerged as the most important expectations for $46 \%$ of the women employees. $15 \%$ preferred recognition. Challenging work, open culture, variety of work for learning opportunities, mental peace and Job satisfaction were also important for some employees (Figure 2).

\subsubsection{Work Life Balance}

Gen Y believes that the working hours have to be fixed to manage work life. Work location is very important for them. Employees prefer the office not to be very far and be well connected to the rest of the city. Flexibility at work is desired by employees. The employees believe that if the work does not require their physical presence, they want work from home option to be available. Work life balance is needed in the earlier stages of life also because employees are more in the stage of figuring out things for themselves. Work life balance is not related to marital status. An employee said she was not married but wanted to learn a new language and engage in some sports. She can do these things only if she has work life balance.

\subsubsection{Recognition}

Employee want the organization to give financial reward for extraordinary performance. However for work done well a pat on the back is enough. When employees stretch and work beyond the regular timings and there is an appreciation given, it acts a motivating factor. Recognition and feedback to be given frequently whether it is positive or negative. They want forums in the organization to provide open feedback like a weekly meeting or casual feedback session. Immediate and prompt feedback helps as opposed to discussing it only when a meeting is scheduled. Social recognition is more valuable than money. Money comes only second.

\subsection{Focus Group 6}

This was a focus group representing employees from different IT/ ITES companies and including of both male and female employees. Job satisfaction, work timings,

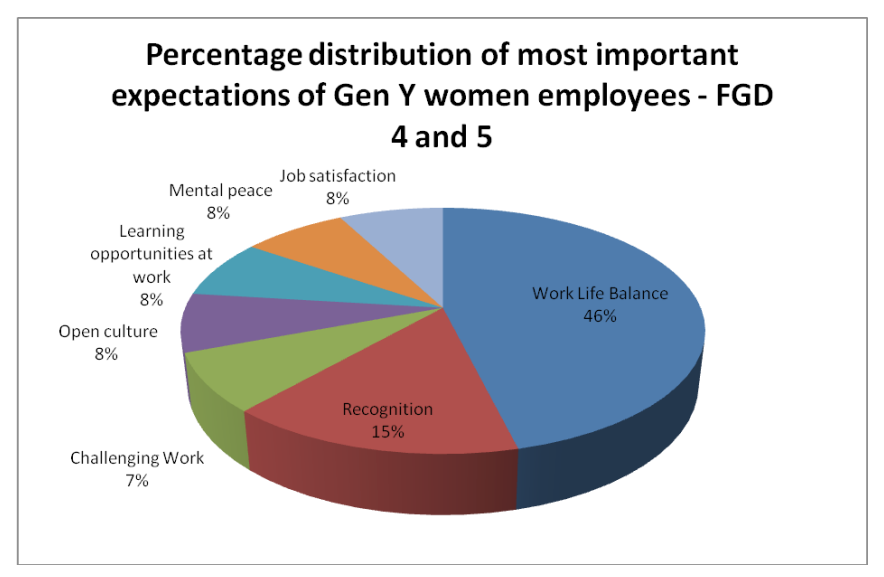

Figure 2. Percentage distribution of most important expectations of Gen Y women employees - FGD 4 and 5. 
area of specialization and career growth were equally important for $25 \%$ of employees each.

\subsubsection{Area of Specialization}

Gen Y believes that IT organizations give training to fresh graduates in many areas during the initial few months of induction. As a result of which, the employees develop interest in few areas. However when the time comes in deployment of the project, the project of the employees is changed based on the needs of the organizations. The employees are constantly moved from one technology to another and sometimes even put in an area where they do not have much technical knowledge. As a result the employee in unable to specialize in their area of interest. Employees want projects where they get to work in the area of their choice and the organization is also able to utilize their technical skills in the project.

\subsubsection{Career Growth}

Many times the companies do not have enough project and many young employees are on the bench. They are asked to participate in training programs during this time. Many times the training is one area and the project they are deployed in is totally in another area. This constant movement across technologies hampers the preferred career path of the employees in the long run. Gen $Y$ wants the organization to consult them and allocate projects considering the preferences of the employee as well.

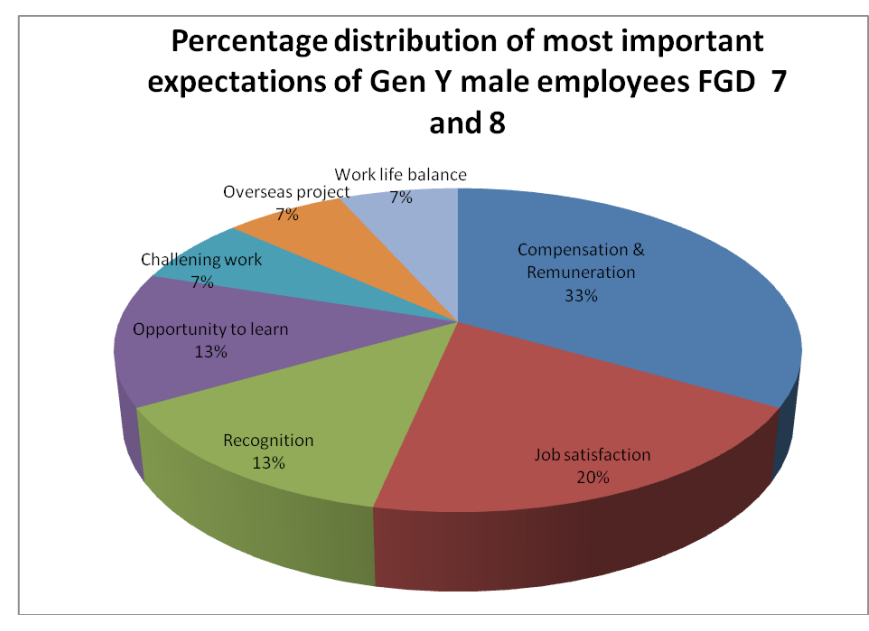

Figure 3. Percentage distribution of most important expectations of Gen Y male employees FGD 7 and 8.

\subsection{Focus Group 7 and 8}

This was a focus group representing male employees from different IT/ ITES companies. Salary emerged as the most important expectation for $33 \%$ of employees. Job satisfaction was another important expectation voted by $20 \%$ of the employees. Recognition and opportunity to learn came third with $13 \%$ of employees voting each of them as the most important expectation. Work life balance, challenging work and overseas opportunity were some of the other important expectations that were discussed by the group. (Figure 3).

\subsubsection{Compensation and Remuneration}

This was predictably the most important expectation for Gen Y male employees. The employee wants competitive salary and perks. In addition to this it was exciting to see that the male employees prefer $30-40 \%$ part of the salary to be dependent upon the performance of the employee and rest $60-70 \%$ as fixed salary. There was a clear preference for performance based variable pay. Salary is not so important to them in the first job though. That time it is the learning opportunities which are important. However as years pass by salary becomes critical.

\subsubsection{Job Satisfaction}

Gen Y employees feel that job satisfaction comes when they are able to use their current skills in their work. They prefer organization give them projects where their skills and experience can be used to the maximum.

\subsection{FGD 9 and 10}

This focus group represents physically differently-abled Gen Y male and female employees from an ITES company. Salary emerged as the most important expectation from $60 \%$ employees and Designation came next for $13 \%$ employees. Job autonomy, training on communication skills career growth and challenging work were some of the other important e $\equiv$ tations that were discussed by the group. (Figure 4).

\subsubsection{Compensation and Remuneration}

Majority of the respondents felt they were being paid inadequately. Given the fact that they are differently abled they have special needs. They have to travel in 


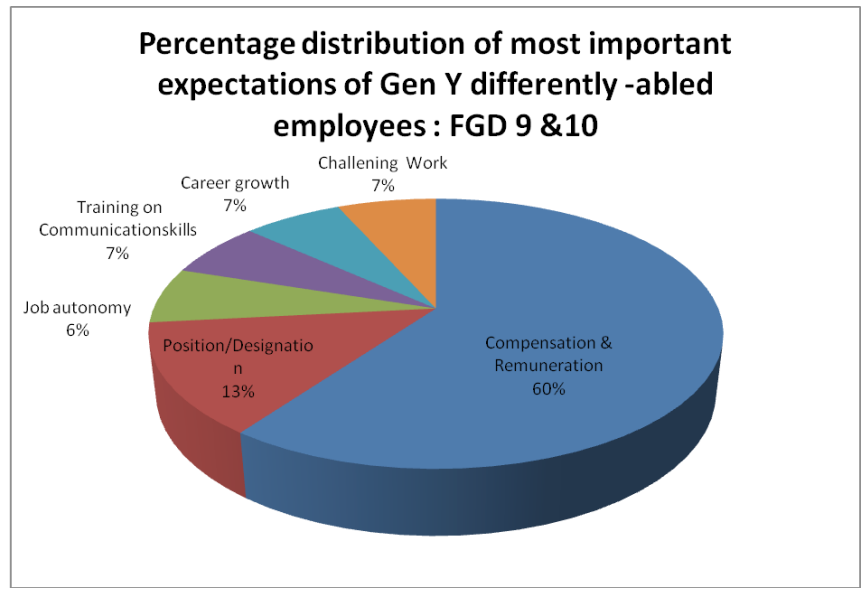

Figure 4. Percentage distribution of most important expectations of Gen Y differently-abled employees FGD 9 and 10.

an auto and it eats into most of their salary. For those who have a family their responsibilities and expenses are just like anyone else. Right now most of them with a family feel they are barely able to meet their monthly expenses and hardly save anything. Thus many of them believe that having a higher salary will make their lives less stressful and comfortable

\subsubsection{Designation}

Many of the Gen Y employees who have been working in the organization a 5-6 years feel that here is not much of career growth and an upward movement in their designations. With many new joinees entering the organization, employees who have given long years of service to the organization need to be moved up the hierarchy.

\subsection{FGD 11}

This focus group represents bothmale and female employees of Gen Y working for an IT company. Opportunities at work emerged as the most important expectation for $46 \%$ of people while recognition and salary were next at $13 \%$ each. Work in domain of one's area of preference, feeling valued in the organization, job satisfaction and work life balance were some of the other important expectations that were discussed by the group.

\subsubsection{Opportunities at Work}

Majority of the participants in this group believed that they would prefer a smaller organization to work where there is greater visibility for their work. It also throws up more options for doing a variety of work. Thus overall it provides more opportunities for learning and career growth.

\subsubsection{Recognition}

Simple recognition and appreciation for good work done is very important. Clients send an email copying the manager and appreciating them for the good work. It also sometime translates into financial rewards. While few prefer spot financial rewards majority preferred that it be reflected at the time of their appraisals.

If we refer to the table 1 above, it is interesting to note the variations in important expectations perceived by the various employees groups within Gen $Y$ based on Gender and Abilities. While compensation and remuneration is most important for men and the differently abled, it does not find a mention at all among the women employees. Work life balance which is the priority for $46 \%$ of women is scored very low by men and does not find a mention with the differently-abled employees. The top three expectations for the three employees groups are completely different from one another. Challenging work is the only expectations which are commonly shared by all employee groups. These expectations if compared to overall expectations of Gen $\mathrm{Y}$ as one whole group are also very different. This supports the premise that different employee groups under Gen $\mathrm{Y}$ will have very different set of expectations. This implies that organizations and HR managers can-not assume and apply a common formula to attract, retain and motivate all Gen Y employees. Gen Y has higher employee expectations as compared to the previous generations. It is also the most diverse generations in the workforce. Therefore it is critical for organizations to attempt to understand and appreciate the specific needs and expectations of each of the employee groups.

\section{A General Overview of Expectations the Psychological Contract of Gen Y Employees}

When expectations of Gen $\mathrm{Y}$ as a whole were collated together, $27 \%$ Gen Y employees considered salary as their most important expectation. 13\% employees indicated career growth as the next most important 
Table 1. A comparison of expectations in the psychological contract across sections of Gen $Y$

\begin{tabular}{lllll}
\hline $\begin{array}{l}\text { Most Important } \\
\text { Expectations }\end{array}$ & Gen Y Male Employees & Gen Y Female Employees & Gen Y Differently-abled Employees & Gen Y Total Employees \\
\hline 1 & Compensation and Remuneration 33\% & Work Life Balance 46\% & Compensation and Remuneration 60\% & Compensation and Remuneration 27\% \\
2 & Job Satisfaction 20\% & Recognition 15\% & Designation 13\% & Career Growth 13\% \\
3 & Recognition 13\% & Job Satisfaction 8\% & Communication Skills Training 7\% & Opportunities at work 10\% \\
4 & Opportunities to learn 13\% & Open Culture 8\% & Career Growth 7\% & Job Satisfaction 9\% \\
5 & Challenging Work 7\% & Learning 0pportunities 8\% & Challenging work 7\% & Work Life Balance 8\% \\
6 & Overseas Projects 7\% & Mental Peace 8\% & Job Autonomy 6\% & Recognition 7\% \\
7 & Work Life Balance 7\% & Challenging Work 7\% & & Challenging Work 6\% \\
8 & & & & Work Environment 5\% \\
9 & & & & Preferred domain of work 2\% \\
10 & & & & Designation 2\% \\
11 & & & Mental Peace 2\% \\
12 & & & Open Culture $1 \%$ \\
13 & & & Work Timings 1\% \\
14 & & & Flexibility 1\% \\
15 & & & Overseas Assignment 1\% \\
16 & & & Transportation 1\% \\
18 & & & Soft Skills Training $1 \%$ \\
19 & & & Feeling valued in the organization 1\% \\
\hline
\end{tabular}

expectation from their organizations. Opportunities at work was the third most important expectation for $10 \%$ employees while Job satisfaction emerged as the fourth important expectations with $9 \%$ employees considering it as the most important workplace expectation. (Figure 5).

\subsection{Compensation and Remuneration}

Many youngsters believe that money is important to them mostly at the time of changing a job. By and large most of the Gen Y employees not only want competitive market pay but also prefer $30-40 \%$ of their salary linked to performance. At the time of joining they prefer organizations are more transparent about the deductions and they prefer to get their actual take home salary rather than the gross figure. Generally it's only after the first pay check that the employees get a shock with high deductions and a low take home salary.

Young employees prefer that they get to choose individually from a wide basket of benefits and allowance. Currently retirement benefits at the beginning of their career do not hold much value for them. However healthcare benefits are very important.

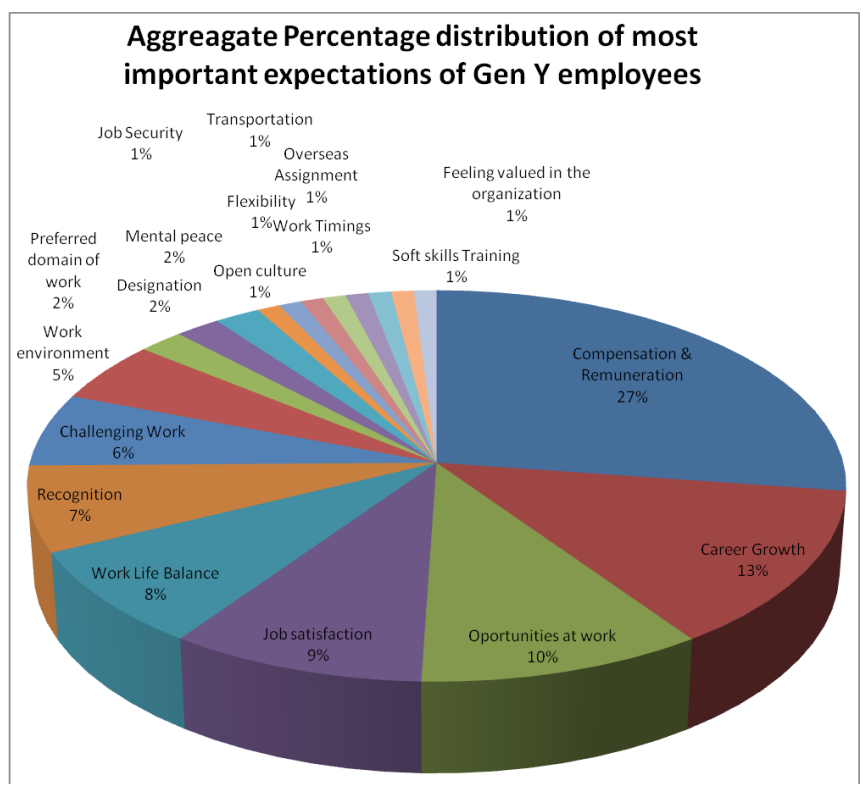

Figure 5. Aggregate percentage distribution of most important expectations of Gen Y employees.

While cash component is always good, some Gen Y employees feel that movie tickets, restaurant passes, ID card discounts at retail stores etc. are good because 
in addition to the money they also give employees an opportunity to socialize beyond regular work.

Facilities like accommodation, food, laundry, gymnasium, and day care for children are all very important and they expect the organization to cater to all these diverse needs of the employees.

Interestingly salary did not appear as an important expectation in all women focus groups which strengthens the viewpoint that the expectations from workplace will be different for employees based on gender.

\subsubsection{Career Growth}

The organizations employing IT/ITES professionals to focus on giving its employees a good career growth path at least for the next 2-3 years. Employees prefer an atmosphere where they are able to develop their career stream. The work to enable the employee to gain new knowledge, improve his/her technical as well people skills and attitude over a period of time. The employees want to make good use of the resources available at work.

Career Growth for Gen $\mathrm{Y}$ also means getting into a higher role at a faster pace and shouldering, more responsibility at work. The employees look for greater exposure with both domestic and overseas clients. Career growth also includes an opportunity to travel abroad. Career growth did not find a mention among the most important expectations of women employees which again indicates that there can-not be a common set of expectations from workplace for a diverse generation like Gen Y.

\subsubsection{Opportunities at Work}

Opportunity at work includes for Gen Y means opportunities of growth and advancement as well as opportunities to learn. Many IT companies keep a buffer bench. In such situations the employees do not get a project for long time and their learning and growth get restricted. Thus it is important for organizations to ensure that enough opportunities are provided to these youngsters for career advancement and growth. The IT field is such that the technology becomes obsolete very soon. Therefore training on latest technology is critical for the success of the organization. Keeping a long term view, organizations must allow the employees the opportunity to learn any new tool and technology even beyond their current projects.

\subsubsection{Job Satisfaction}

Employees feel the job satisfaction comes when they are able to use their current skills in their work. They prefer organization give them projects where their skills and experience can be utilized to the maximum. They would expect the organizations to keep their area of interest in mind while allocating them roles and projects such that their job satisfaction is enhanced.

\subsubsection{Work Life Balance}

Work life balance finds itself a place among the top expectations of Gen Y employees which is unique if compared to research few years back. This indicates a greater desire for balance among professional and personal life than some of the previous generations.

\section{Main Discussion: Key Emergent Points}

The above findings indicate that Compensation and remuneration, Career growth and Opportunities at work have emerged the top three important expectations of Gen Y employees. The organizations can make attempts to understand the unique needs of women, men and differently abled employees under each of these three categories and make best efforts to fulfill them. By doing so, the organization will fulfill its obligations and all employees will be more happy and satisfied with their job. This will not only lead to increased motivation among the existing employees, but also help in attracting young talent through word of mouth publicity and retain them.

Another important observation was that Compensation and remuneration was voted as the most important expectation by only $27 \%$ employees. The percentage distribution in terms of the importance given to expectations is quite varied and a large number of expectations have been listed in Exhibit 5. Gen Y as a generation does not have very many things in common from workplace. The exploratory data collected through this focus group discussion confirms the fact that in order to manager diverse employee groups in an organization like women 
and differently-abled employees within Gen Y, the HR managers may need to explore the specific psychological contract items and understand expectations of each of the groups. Customized employee contracts to fit different need of diverse employee groups need to be designed by the organizations based on their discussions with these groups.

\section{Conclusion: Need for a Proactive Approach to Managing Diverse Employee Groups}

Based on the above discussion points we can understand that the presence of compensation and remuneration, career growth and opportunities at work are prominent expectations across Gen Y. Work life balance expectations is more prominent in women group etc. Designation and communication skills training are very unique to the differently-abled category and not shared by the other two groups. Whereas compensation and remuneration is not an important expectation for women at all.

An understanding of these variations and patterns that we find among work place expectations will help us to create a reliable framework to manager diverse employee groups in an organization. It can ensure that needs and expectations of different employees are understood and met by the organization. This proactive approach to managing diversity will ensure that violation of psychological contract does not happen for minority employees groups like women and differently-abled due to lack of knowledge of their unique needs and wants. This will help in curbing intentional discrimination as well as designing customized employee experiences in line with their expectations at work which could curb unhealthy attrition. Additionally, the common feature of the psychological contract items can help managers build a culture of inclusion and collaboration among different employee groups at work.

\section{Limitation of the Paper and Suggestions for Future Research}

This is an exploratory study and is not a CASE study of a single organization. The authors abide by the research norm that the findings reported cannot be generalized without appropriate statistical testing on a larger sample. This study has been able to explore expectations of Gen $\mathrm{Y}$ and showcase how these expectations may be different for women and differently-abled employees. Future research is needed using quantitative techniques on a large sample size to be able to generalize the results

This study is limited to IT/ITES employees in Bengaluru city due to constraints on time and cost. Future studies can explore these expectations at other geographical regions in the country.

The current study tries to study men, women and differently-abled Gen Y employees due to time constraints. Future studies can also explore others dimensions of diversity like race, caste, sexual orientation, socio-economic background and religious inclinations etc. which are also very relevant sources of employs diversity in the Indian context. ${ }^{1}$

\section{Acknowledgement}

We are extremely thankful to all the IT/ITES organizations and their employees who participated in the study. We are also extremely thankful to the reviewers for their valuable comments in improving the quality of this research article.

\section{References}

Aggarwal, U., Bhargava S. (2009). Exploring psychological contract contents in India: the employee and employer perspective. Journal of Indian Business Research. 1(4):238-51.

Chrobot Mason, D. L. (2003). Keeping the promise Psychological contract volations for minority employees. Journal of Managerial Psychology. 18(1):22-45.

Cynthia, L., Liu, J., Rousseau, D., Hui, C., Chen Z. X. (2011). Inducements, contributions and fulfillment in new employee psychological contracts. Human Resource Management, 50(2):201-26.

Deal, J. J., Altman, D. G., Rogelberg S. G. (2010). Millennials at Work: What We Know and What We Need to Do (If Anything), Journal of Business and Psychology, 25(2):191-9.

De Vos, A., Buyens, D., Schalk, R. (2003). Psychological contract development during organizational socialization: 
adaptation to reality and the role of reciprocity. Journal of Organizational Behavior, 24(5):537-59.

De Vos, A., De Stobbeleir, K., Meganck, A. (2009). The relationship between career related antecedents and graduate's anticipatory psychological contracts. Journal of Business Psychology. 24(3):289-98.

Erickson, T. (2008). Plugged in: The Generation Y guide to thriving at Work. Boston, Massachusetts: Harvard Business Press.

Freese, C., Schalk, R. (2008). How to measure the psychological contract? A critical criteria-based review of measures. South African Journal of Psychology. 38(2):269-86.

Grant, D. (1999). HRM, Rhetoric and the psychological contract: A case of 'easier said than done. The International Journal of Human Resource Management. 10(2):327-50.

Harvey, C. P., Allard, M. J. (2009). Understanding and managing diversity: readings, cases and exercises. New Jersey: Pearson Education Inc.

Herriot, P., Manning, W. E. G., Kidd, J. (1997). The content of the psychological contract. British Journal of Management. 8:151-62.

Ho, V. T. (2005). Social influence on evaluations of psychological contract fulfilment. Academy of Management Review. 30(1):113-28.

Ivancevich, J. M., Gilbert, J. A. (2000). Diversity management: time for new approach. Public Personnel Management. 29(1):75-92.

Jayne, M. E. A., Dipboye R. L. (2004). Leveraging diversity to improve business performance: research findings and recommendations for organizations. Human Resource Management. 43(4):409-24.

Kelley Patterson, D., George, C. (2002). Mapping the contract: an exploration of the comparative expectations of graduate employees and human resource managers within the hospitality, leisure and tourism industries in the United Kingdom. Journal of Services Research. 2(1):55-74.

Konrad,A. M. (2003). Defining the domain of workplace diversity scholarship. Group and Organization Management. 28(1):4-17.

Kotter, John Paul. 1973. 'The Psychological Contract: Managing the Joining Up Process', California Management Review. 15:3: 91-99.

Krivokapic-Skoko, B., O’Neil, G., Dowell, D. (2009). Assessing the contents of the psychological contracts: A Cross Sectional surveys of the academics at an Australian University, New Zealand Journal of Employment Relations, 34(2):4-28.

Kundu, S. C. (2003). Workforce diversity status: a study of employee's reactions. Industrial Management and Data Systems. 103(3-4):215-26.
Lester, S. W., Kickul, J. (2001). Psychological contracts in the $21^{\text {st }}$ century: what employees value most and how well organizations are responding to these expectations? Human Resource Planning. 24(1):10-21.

Lester, S. W., Turnley, W. H., Bloodgood, J. M., Bolino, M. C. (2002). Not seeing eye to eye: differences in supervisor and subordinate perceptions of and attributions for psychological contract breach. Journal of Organizational Behavior. 23(1):39-56.

Mamtha, J., Satya Nandini, A. (2013). Career Expectations of Gen Y IT employees with special reference to Bangalore. Global Research Analysis. 2(6):139-40.

Mercer. (2012). Diversity and Inclusion: An Asia Pacific Perspective Research Report.

NASSCOM. (2011). Diversity in action. NASSCOM PWC.

Patrick, H. A. (2008). Psychological Contract and Employment Relationship. The Icfai University Journal of Organizational Behavior. 7(4):7-24.

Patrick, H. A., Rajkumar V. (2012). Managing Workplace Diversity: Issues and Challenges. Sage Open. 1-15.

Roberts, E. M. (2011 Nov 4). Cornell HR Review. Retrieved: http://www.cornellhrreview.org/creating-stronger-diversity-initiatives-in-employment-settings/

Robinson S. L., Rousseau D. (1994). Violations in the psychological contract not the exception bu the norm. Journal of Organizational Behavior. 15(3):245-59.

Roehling, M. V., Cavanaugh M. A., Moynihan L. M., Boswell W. R. (2000). The nature of the new employment relationship: A content analysis of the practioner and academic literatures. Human Resource Management. 39(4):305-20.

Rousseau, D. M. (1990). New Hire Perceptions of their own and their Employer's Obligations: A study of Psychological Contracts. Journal of Organizational Behavior. 11(15):389-400.

Rousseau, D. M. (1995). Psychological contracts in organizations: understanding the written and unwritten agreements. London: sage.

Rousseau, D. M. (2004). Psychological contracts in the workplace: understanding the ties that motivate. Academy of Management Executive. 18(1):120-7.

Sims, R. R . (1994). Human Resource Management's Role in Clarifying the New Psychological Contract. Human Resource Management. 33(3):373-83.

Sparrow, P. R. (1996). Transitions in the psychological contract: some evidence from the banking sector. Human Resource Management Journal. 6(4):75-92.

Woodward, N., Saini, D. S. (2006). Diversity management issues in USA and India: some emerging perspective. In: Singh, P., Bhatnagar J., Bhandarker A., editor. Future of Work: Mastering Change. New Delhi: Excel Books. 


\section{About the Author(s)}

Prof. Jyoti Joshi Pant is working as an Assistant Professor in the area of Organization Behavior and Human Resource Management at Prin. L. N. Welingkar Institute of Management Development \& Research, Bengaluru. She completed her MBA from T. A. Pai Management Institute, specializing in Human Resource Management and General Management. She has more than 8 years of corporate HR experience and 3 years of academic experience. She has done consultancy assignments on Belbin Inventory and designed and delivered training on Multi-Generational Collaboration at work for corporate clients. She conducts management development programs in the area of leadership, motivation and personality development. She is currently pursuing her Ph.D. in the area of Diversity Management and Generation Y from Jain University, Bengaluru. She can be reached at reached at jyoti.pant@welingkar.org.
Dr. Vijaya. $\mathbf{V}$ is working as a Professor at the Indian Institute of Management, Trichy, in the area of Organizational Behaviour and Human Resource Management. She has completed her Ph.D. from Indian Institute of Technology, Madras. As a researcher, she has worked on sponsored projects of DSIR and ICSSR. She has published empirical and conceptual articles and presented in various national and international forums. She is a UGC Fellow and has also qualified for the ICSSR Young Social Scientist Research award. Her core competence is HR Analytics and her research interests include the social psychology of teams and organizations, how knowledge develops through Networks and Relationships \& the Psychological Contract. She can be reached atvijaya@iimtrichy.ac.in. 